\title{
PRODUKSI SEDIAAN KOMBUCHA DARI DAUN PERMOT (Passiflora foetida L) SECARA FERMENTASI
}

\author{
Herwin, Rachmat Kosman, Iswan Siami \\ Fakultas Farmasi Universitas Muslim Indonesia \\ Email : herwinfarmasi@gmail.com
}

\begin{abstract}
A research has been done about profit of permot leaves (Passiflora foetida L.) by using culture of kombucha with the aim to know the use of permot leaves (Passiflora foetida L.) as preparation of kombucha in a fermentation. Permot dried leaves boiled in $1000 \mathrm{ml}$ water until boiling then got extract of permot. Extract of permot leaves added with 100 gram glucose and $10 \%$ of inoculum kombucha culture then fermented for $5-12$ days. The results of kombucha preparation from permot leaves then testing with organoleptic, measuring $\mathrm{pH}$ and total acid test. Based of the results in preparation kombucha permot leaves (Passiflora foetida L.) showed that the color-test organoleptic with hedonic method was obtained values 2.5, flavor 1.9, and taste 2.4. $\mathrm{pH}$ measurement before fermentation is 4 and after that is 3 with total acid of $0.66 \%$.
\end{abstract}

Key Word : Permot Leaves (Passiflora foetida L.), Fermentation, Kombucha of Preparation

\section{PENDAHULUAN}

Sejak zaman dahulu, manusia selalu berusaha untuk memproduksi berbagai sediaan makanan dan minuman baik dari tanaman atau tumbuhan dengan cara fermentasi misalnya dalam fermentasi sediaan kombucha. Salah tatu tumbuhan yang dapat diproduksi sediaan kombucha adalah daun permot yang mengandung hidrosianat dan laktone. Buah masak mengandung $\mathrm{Ca}, \mathrm{P}, \mathrm{Fe}$. Selain itu, permot juga mengandung alkaloid, steroid, saponin, dan flavanoid.
Permot (Passiflora foetida L.) merupakan tanaman yang termasuk dalam jenis tanaman gulma dan juga tanaman perdu. Namun memiliki bunga yang begitu indah mirip dengan bunga tanaman markisah. Permot adalah tanaman herba yang berasal dari Amerika tropis yang dapat ditemukan pada ketinggian 1 - $1000 \mathrm{~m}$ dpl, tumbuhan yang hidupnya di tempat-tempat liar atau terbuka yang mendapat cahaya matahari, seperti di semak-semak, tanah lapang yang terlantar, atau merambat di pagar yang berkhasiat sebagai obat batuk, radang 
kelenjar, insomnia, darah tinggi, bengkak, kencing berlemak, dan borok (Dalimartha dan Yuniarti, 2008).

Permot (Passiflora foetida L.) secara empiris berkhasiat untuk batuk karena paru-paru panas, radang kelenjar getah bening leher (servikal limfadenitis), sulit tidur (insomnia), gelisah, mimpi buruk, kelelahan kronis yang abnormal (neurasthenia), darah tinggi (hipertensi), bengkak (edema), kencing berlemak (chyluria), dan koreng, skabies, borok (ulcus) pada kaki. Juga buah berkhasiat menghilangkan nyeri (analgetik) dan memperkuat paru-paru (Dalimartha dan Yuniarti, 2008).

Salah satu obat tradisional yang cukup banyak digunakan dimasyarakat dan terbukti bermanfaat adalah teh kombcuha yang merupakan suatu ramuan minuman kuno, yang terjadi atas hasil simbiosis murni dari bakteri dan ragi yang berkhasiat dan menyembuhkan beberapa penyakit, diantaranya sebagai agen propofilaktit dan terapeutik untuk kanker terutama pada stadium awal, antiinflamasi, detoksikasi melancarkan pencernaan, menetralisir asam urat sehingga bermanfaat gout, rematik, arthritis, juga sebagai peluruh batu ginjal. Dimana teh dengan berbagai kandungan kimia yang mirip dengan kandungan kimia dari permot. Hal inilah yang mendasari untuk dilakukan penelitian dalam pembuatan sediaan kombucha dari daun permot (Passiflora foetida L.).

\section{METODE PENELITIAN}

\section{A. Waktu dan Tempat Penelitian}

Penelitian ini direncanakan akan dilakukan pada bulan Mei 2012 sampai selesai. Dilaksanakan di Laboratorium Mikrobiologi Fakultas Farmasi Universitas Muslim Indonesia Makassar.

\section{B. Alat dan Bahan Penelitian}

\section{Alat-alat yang digunakan:}

Alat-alat yang dipakai adalah Autoklaf (Smic Model YX-280 B), enkas, Erlenmeyer 1000 ml (Iwaki Pyrex), gelas kimia $1000 \mathrm{ml}$ (Iwaki Pyrex), gelas ukur $100 \mathrm{ml}$ (Iwaki pyrex), kertas $\mathrm{pH}$ universal, dan timbangan analitik (Chyo).

2. Bahan-Bahan yang digunakan

Bahan-bahan yang digunakan adalah air suling, glukosa, daun permot (passiflora foetida L), kultur kombucha, $\mathrm{NaOH} 0,1 \mathrm{~N}$.

\section{Prosedur Penelitian}

\section{Strelisasi Alat dan Bahan}

Alat-alat yang digunakan dicuci bersih dengan air kemudian dikeringkan. Untuk 
gelas ukur dan kain saring disterilkan di autoklaf dengan suhu $121^{\circ} \mathrm{C}$ selama 15 menit dan botol fermentasi serta batang pengaduk disterilkan di oven dengan suhu $180^{\circ} \mathrm{C}$ selama 2 jam.

\section{Penyiapan Sampel Penelitian}

\section{a. Pengambilan Sampel}

Sampel daun permot (Passiflora foetida L.) diperoleh dari kota Makassar. Kultur kombucha diperoleh dari Laboratorium Fakulats Farmasi Universitas Muslim Indonesia.

b. Pengolahan Sampel

Daun permot dipetik pada pukul 10.00 wita dan disortasi untuk menghilangkan kotoran yang melekat pada daun permot, dikeringkan dengan cara diangin-anginkan dengan tidak terkena sinar matahari langsung dan dihaluskan untuk proses ekstraksi.

\section{Penyiapan Kultur Kombucha}

Ditimbang $15 \mathrm{~g}$ teh hijau lalu dimasukkan ke dalam panci infus dengan air secukupnya dan dipanaskan di atas tangas air selama 15 menit terhitung mulai suhu mencapai $90^{\circ} \mathrm{C}$ sambil sesekali diaduk. Disaring ke dalam wadah kaca, setelah disaring dicukupkan volumenya dengan air matang melalui ampas hingga $100 \mathrm{ml}$. infus teh hijau ditambahkan gula pasir 10\% kemudian ditambahkan air matang hingga $1000 \mathrm{ml}$ lalu diaduk sampai gula benarbenar larut dan didinginkan pada suhu kamar sampai suhunya kurang lebih $35^{\circ} \mathrm{C}$. lembaran jamur kombucha dimasukkan ke dalam toples yang berisi infus teh, kemudian ditutup dengan kain kasa steril yang rapat dan diikat lalu didiamkan. Difermentasi hingga terbentuk lembaran jamur kombucha yang baru.

4. Pembuatan

Kombucha Permot

Rebus satu liter air hingga mendidih dalam wadah stainless steel atau panci. Kemudian tuangkan 10 gram daun permot ke dalamnya. Biarkan beberapa menit (sekitar 15 menit) hingga daun permot melarut. Pisahkan ekstrak permot dengan ampas permot dengan cara disaring menggunakan kain saring. 
Selagi air masih panas, lalu tambahkan gula sebanyak 100 gram aduk hingga gula melarut sempurna. Biarkan suhu larutan permot turun hingga mencapai suhu ruangan (sekitar 25 $27^{\circ} \mathrm{C}$ ). Masukkan larutan permot tersebut ke dalam toples kaca Kemudian inokulasi kultur kombucha sebanyak $10 \%$ dan ditutup dengan menggunakan kain kasa. Dibiarkan pada suhu fermentasi selama 7 - 12 hari. Lapisan kombucha diangkat kemudian dicuci dengan air bersih. Hasil fermentasi selama 12 hari dimasukkan dalam botol kemasan kemudian disterilkan.

\section{Pengujian Sediaan Kombucha}

\section{Permot}

\section{a. Uji Organoleptik}

Uji organoleptik yang dilakukan dalam penelitian ini hanya meliputi pengamatan terhadap warna, aroma dan rasa (hedonik) (Soekarto, 1985).

\section{Pemilihan Panelis}

$$
\begin{aligned}
& \text { Pengujian ini } \\
& \text { berdasarkan panelis } \\
& \text { yang dipilih sebanyak } 10 \\
& \text { orang yang memenuhi } \\
& \text { kriteria sebagai panelis }
\end{aligned}
$$

$$
\begin{aligned}
& \text { yaitu dalam kondisi } \\
& \text { sehat. }
\end{aligned}
$$

\section{Teknik Pengujian}

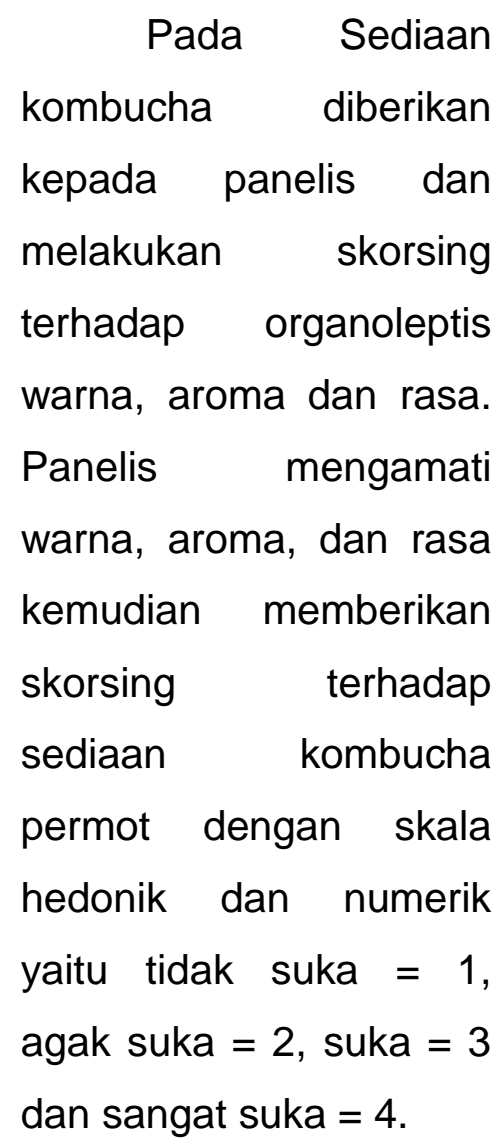

\section{b. Pengukuran pH}

Diambil

produk

kombucha kemudian diukur pHnya $(\mathrm{pH} \quad 2,7 \quad-\quad 3,2)$ dengan menggunakan kertas $\mathrm{pH}$ universal.

\section{c. Uji Kadar Total Asam}

Sebanyak $10 \mathrm{ml}$ kombucha permot dimasukkan dalam labu Erlenmeyer kemudian ditambahkan indikator fenolftalein $1 \%$ (sebanyak 2 - 3 tetes), dititrasi dengan 
menggunakan $\mathrm{NaOH} 0,1 \mathrm{~N}$

sampai larutan berwarna

merah puda (pink) dan

dihitung beberapa $\mathrm{ml} \mathrm{NaOH}$ yang digunakan. Total asam

dihitung sebagai asam asetat.

\section{HASIL PENELITIAN}

Tabel 1. Hasil fermentasi kombucha permot (Passiflora foetida L.) selama 12 hari

\begin{tabular}{cccccc}
\hline \multirow{2}{*}{ Sampel } & \multicolumn{5}{c}{ Uji Sediaan } \\
\cline { 2 - 5 } & Warna & Aroma & Rasa & Total Asam (\%) \\
\cline { 2 - 6 } & 2,5 & 1,9 & 2,4 & 3 & 0,66 \\
\hline Kombucha Permot & & & &
\end{tabular}

\section{PEMBAHASAN}

Permot merupakan tanaman yang termasuk dalam jenis tanaman gulma dan juga tanaman perdu. Herba yang berasal dari American tropis ini tumbuh di tempat-tempat yang liar atau terbuka, seperti di semak-semak, tanah lapang yang terlantar atau merambat dipagar. Buah, biji, dan daun mengandung substansi yang tidak stabil, yaitu asam hidrosianat dan laktone. Buah masak mengandung $\mathrm{Ca}$, $\mathrm{P}$, Fe. Selain itu, permot juga mengandung alkaloid, steroid, saponin, dan flavanoid.

Kombucha atau dikenal masyarakat Indonesia sebagai jamur teh, atau jamur dipo, adalah produk minuman tradisional hasil fermentasi larutan teh dan gula dengan menggunakan campuran kultur bakteri dan khamir yang difermentasi selama 7 - 12 hari sehingga diperoleh citarasa asam dan terbentuk lapisan nata.
Jamur tersebut terdiri dari gelatinoid serta membran jamur yang liat dan berbentuk piringan bulat serta hidup dalam lingkungan nustrisi tehmanis yang akan tumbuh secara berulang sehingga membentuk susunan piringan berlapis. Piringan pertama akan tumbuh pada lapisan paling atas yang akan memenuhi lapisan, kemudian disusul oleh pertumbuhan piringan berlapis-lapis dibawahnya yang akan menebal secara fermentasi.

Fermentasi pada awalnya hanya menunjukkan pada suatu peristiwa alami pada pembuatan anggur yang menghasilkan buih (ferment berarti buih). Fermentasi merupakan perubahan kimiawi secara okisdatif dari mikroorganisme dalam substrat dengan hasil pemecahannya berupa senyawa-senyawa yang lebih kompleks serta terjadi perubahan gula menjadi alkohol yang melibatkan kerja 
enzim. Fermentasi merupakan suatu proses pemecahan karbohidrat dan asam amino secara anaerobik, yaitu tanpa memerlukan okesigen. Senyawa yang dapat dipecah dalam proses fermentasi terutama karbohidrat, sedangkan asam amino hanya dapat difermentasi oleh beberapa jenis bakteri tertentu.

Fermentasi dapat meningkatkan nilai gizi bahan yang berkualitas rendah serta berfungsi dalam pengawetan bahan dan merupakan suatu cara untuk menghilangkan zat antinutrisi atau racun yang terkandung dalam suatu makanan. Secara umum pada proses fermentasi kombucha terjadi simbiosis antara Acetobacter xylinum dan Saccharomyces serevisiae. Simbiosis ini menghasilkan zat asam dan alkohol yang menghalangi pertumbuhan mikroorganisme asing yang tidak berasal dari jamur kombucha. Zat asam terbentuk karena adanya aktivitas mikroba yang ada di dalamnya secara terus menerus sampai zat gula di dalamnya habis. Selain zat asam, fermentasi ini juga menghasilkan polisakarida (selulosa). Bakteri Acetobacter xylinum mampu mengoksidasi glukosa menjadi asam glukonat dan asam organik lain pada waktu yang bersamaan. Selain itu,
Acetobacter xylinum juga dapat mensintesis glukosa mejadi polisakarida atau selulosa yang berupa serat-serat putih.

Terbentuknya sellulosa dikarenakan adanya penambaham gula yang dimanfaatkan sebagai sumber karbon bagi pertumbuhan Acetobacter xylinum. Acetobacter xylinum merubah gula dalam bentuk lain (maltose, sukrosa, dan lain-lain) menjadi bentuk glukosa dan fruktosa dibantu dengan kondisi asam media fermentasi.

Selama proses fermentasi gula berfungsi sebagai sumber karbon yang akan menstimulasi pertumbuhan Acetobacter xylinum sehingga mempercepat proses pembentukan selulosa. Persentasi gula dalam medium fermentasi kombucha permot dapat meningkatkan jumlah selulosa yang terbentuk. Semakin tinggi jumlah selulosa maka akan menyebabkan ketebalan nata semakin meningkat.

Semakin tinggi asam organik yang terdapat dalam kombucha maka semakin tinggi pula total asamnya. Hal ini disebabkan oleh semakin lamanya waktu fermentasi, maka akan semakin banyak asam asetat yang terbentuk sebagai hasil metabolisme Acetobacter xylinum. Semakin lama fermentasi, maka hasil fermentasi 
akan semakin asam. Konsentrasi asam asetat dalam kombucha hanya meningkat sampai batas tertentu lalau mengalami penurunan. Hal ini terjadi karena pemanfaatan asam asetat lebih lanjut oleh Acetobacter xylinum ketika jumlah gula dalam sediaan kombucha mulai habis. Penurunan kadar asam ini dikarenakan fermentasi etanol oleh khamir juga mengalami penurunan dikarenakan $\mathrm{pH}$ yang sangat rendah serta mulai habisnya gula dalam larutan.

Pada umumnya semakin meningkatnya kandungan asam suatu bahan maka nilai $\mathrm{pH}$ akan semakin turun. Penurunan $\mathrm{pH}$ minuman kombucha diduga disebabkan oleh peningkatan konsentrasi zat-zat asam selama proses fermentasi. Zat asam yang terlarut akan melepaskan proton yang menyebabkan penurunan $\mathrm{pH}$. Sreeramulu et, al., (2000), menyatakan bahwa penurunan $\mathrm{pH}$ terjadi karena selama proses fermentasi khamir dan bakteri mensintesis sukrosa menjadi asamasam organik, seperti asam asetat dan asam glukonat dan beberapa asam organik lainnya, sehingga dengan peningkatan konsentrasi asam-asam organik tersebut mengakibatkan penurunan $\mathrm{pH}$ pada medium fermentasi.
Berdasarkan hasil pengujian organoleptik terhadap 10 orang panelis yang mewakili konsumen dengan menggunakan metode hedonik dengan tujuan untuk mengetahui tingkat kesukaan produk fermentasi kombucha permot sebagai minuman diperoleh nilai rata-rata hedonik yaitu 2,5. Hasil kriteria penilaian skala organoleptik menunjukkan bahwa terdapat lima orang yang menyukai warna kombucha permot dan lima orang yang agak suka. Pada pengujian organoleptik aroma kombucha permot diperoleh nilai 1,9. Sedangkan pada pengujian organoleptik rasa diperoleh nilai 2,4 .

Pengukuran nilai $\mathrm{pH}$ kombucha permot dilakukan sebelum dan setelah difermentasi selama 12 hari, dimana hasil pengukuran tersebut yaitu, sebelum fermentasi $\mathrm{pH}$ medium kombucha permot adalah 4 dan pada saat setelah fermentasi nilai $\mathrm{pH}$ mediumnya adalah 3. Besarnya harga $\mathrm{pH}$ tersebut disebabkan karena suasana asam yang ditimbulkan oleh asam-asam organik termasuk asam asetat yang terbentuk selama proses fermentasi berlangsung.

Kadar total asam dihitung sebagai asam asetat sebagai salah satu produk fermentasi kadar total 
asam. Pada pengujian ini terlihat bahwa kadar total asam kombucha permot adalah sebanyak 0,66 \%. Kadar totas asam yang rendah kemungkinan disebabkan karena proses fermentasi yang belum sempurna sehingga asam asetat sebagai salah satu produk akhir kadarnya rendah. Hal ini menunjukkan bahwa penambahan permot dapat mempengaruhi kadar total asamnya.

Kadar total asam yang semakin tinggi disebabkan oleh proses fermentasi yang berlangsung sempurna yang menghasilkan asam asetat, asat sitrat dan asam-asam organik lainnya dengan kadar yang lebih tinggi.

\section{KESIMPULAN}

Dari hasil penelitian yang telah dilakukan dapat disimpulkan bahwa daun permot dapat digunakan sebagai bahan produk sediaan kombucha dengan nilai hedonik pada organoleptik warna 2,5, aroma 1,9 dan rasa 2,4 dengan nilai $\mathrm{pH} 3$ dan total asamnya $0,66 \%$.

\section{DAFTAR PUSTAKA}

Cronquist, A., 1981, An Integrated System of Classification of
Flowring Plants, Columbia University Press. New York

Dalimartha, S., 2008, Atlas Tumbuhan Obat Indonesia, Jilid 3, Puspa Swara. Jakarta

Hidayat, N., 2006, Mikrobiologi Industri, Andi. Yogyakarta

Molangga, D., 2006, Isolasi dan Identifikasi Komponen Kimia Ekstrak dieti eter Herba Permot (Passiflora foetida L.) Asal Kabupaten Pinrang, (Skripsi). Makassar : Universitas Muslim Indonesia

Muchtadi, T., R.., 2010, Teknologi Proses Pengolahan Pangan, Alfabeta. Bandung

Naland, H., 2008, Kombucha Teh dengan Seribu khasiat, Agromedia Pustaka. Jakarta

Naland, H., 2004, Kombucha Minuman Nikmat Yang Menyehatkan, Herba, Agromedia Pustaka, Jakarta

Riadi dan Lieke, 2007, Teknologi Fermentasi, Graha ilmu, Yogyakarta

Soekarto, S.T., 1985, Penilaian Organoleptik untuk Industri Pangan dan Hasil Pertanian, Pusbangtepa, IPB-press. Bogor

Yuniarti T., 2008, Ensiklopedia Tanaman Obat Tradisional, Media Pressindo, Yogyakarta 